in a viable pregnancy, provided that maternal efficiency remained constant.

The only way to resolve these questions is to make an effort to inspect all spontaneously aborted fetuses and to record any malformations found. Mothers are very willing to keep products of conception, and should be asked to do so if bleeding occurs early in prgenancy. Sadly their medical attendants often fail to show any interest in the fetus once it is aborted. We have received several fetuses with obvious neural tube defects that had not been medically diagnosed, or whose state had not been recorded in the notes.

Before these questions are resolved there is no way of testing the hypothesis put forward by Dr. Roberts and Mrs. Lloyd. There is, however, an alternative possible explanation of their findings. At least $50 \%$, and arguably $80 \%$, of all truly spontaneous abortions are due to fetal chromosomal anomaly. It is therefore just possible that the observed inverse relationship between abortion rate and prevalence of neural tube defects is secondary to one between incidence of fetal chromosome anomaly and neural tube defect. Assuming that trisomy 21 behaves like the prenatally lethal chromosome components, a comparison of rates of mongolism in their areas $\mathrm{A}$ and $\mathrm{B}$ might throw some light on this question.-We are, etc.,

Eva Alberman MichaEL CREASY Paul E. Polani

Paediatric Research Unit Guy's Hospital Medical School,
London S.E.1

1 Record, R. G., and Mckeown, T., British fournal of Social Medicine, 1950, 4, 26.

2 McDonald, A. D., British fournal of Preventive and Social Medicine, 1971, 25, 220.

\section{Endotoxic Shock after Transhepatic Cholangiography}

SIR,-The case report of Mr. R. C. Lallemand and Mr. G. Blackburn describing endotoxic shock following transhepatic cholangiography in a patient with carcinoma of the proximal bile ducts ( 8 September, $p$. 541) emphasized certain important points relevant to the management of tumours at this site.

Most important, an operation to exclude biliary obstruction in a patient with suspected extrahepatic cholestasis is incomplete unless either a cholangiogram or the passage of sounds has shown that all the intrahepatic as well as the extrahepatic ducts are unobstructed. That the authors' patient developed a biliary fistula after liver biopsy is thus hardly surprising, but in this case proved to be a blessing in disguise as it led to reoperation and the construction of a biliary-enteric anastomosis proximal to the carcinoma.

$A$ recent report by myself and my colleagues at the Lahey Clinic ${ }^{1}$ of 103 patients with carcinoma of the proximal bile ducts showed that excision of the primary tumour is only rarely feasible. However, as in the case referred to above, the great majority of patients died not as a direct result of their carcinoma but from recurrent cholangitis and liver failure secondary to persistent biliary obstruction. The report showed also that adequate biliary decompression using a variety of surgical pro- cedures, repeated in several patients, led to prolonged survival in some cases. In fact, two of the patients survived for nine years with intermittent bypass procedures. If it is not possible to bypass the tumour, then forcible dilatation of the malignant stricture followed by prolonged intubation may be worth while.

With regard to cholangitis in patients with carcinoma of the proximal bile ducts, we found that it was only rarely a presenting feature but developed frequently once the biliary tract had been operated upon.-I am, etc.,

St. Bartholomew's Hospital,

ALEXANDER P. ROSS

\section{London E.C.1}

1 Ross, A. P., Braasch, J. W., and Warren, K. W., 923 .

\section{Intranasal Administration of Synthetic}

Gonadotrophin-releasing Hormone

SIR,-Since the 1960s the intranasal route has been used with success in the administration of oxytocin, ${ }^{1}$ which is structurally a polypeptide hormone with a molecular size resembling that of luteinizing hormone/ follicle stimulating hormone-releasing hormone (LH/FSH-RH; LRH), which was synthesized in $1971 .{ }^{2}$ In view of the expected increased clinical use of LH/FSH-RH it was considered useful to study also this polypeptide hormone for any variation of its effect with different routes of administration Quite recently the first results of intranasal administration of $\mathrm{LH} / \mathrm{FSH}-\mathrm{RH}$ in men have been reported. ${ }^{3}$

We studied 10 amenorrhoeic women who were given $100 \mu \mathrm{g}$ of LH/FSH-RH (Hoechst) intravenously. The effect was assessed from serial measurements of the plasma levels of LH and FSH, determined by double antibody radioimmunoassays as described elsewhere. ${ }^{4}$ The response was compared with those produced by $2 \mathrm{mg}$ of LH/FSH-RH given intranasally and by 2
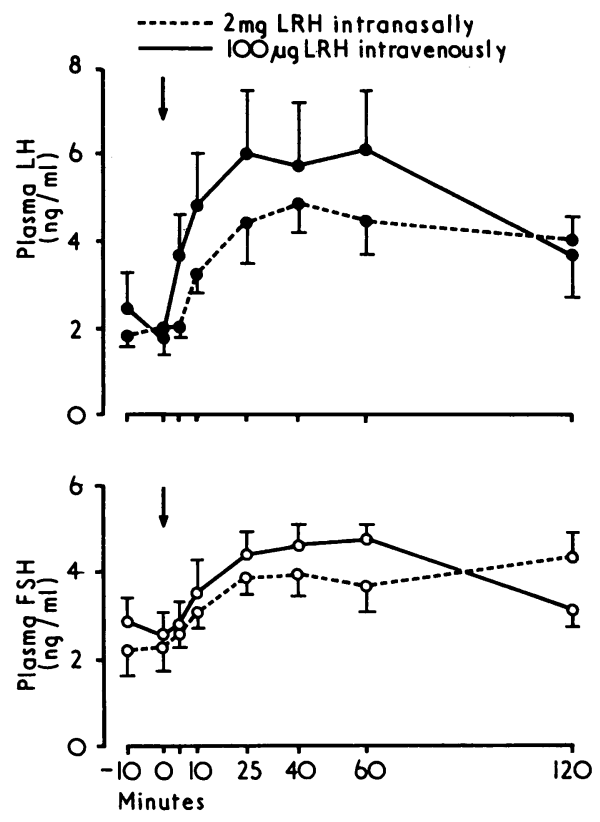

Plasma levels (mean \pm S.E.M.) of LH and FSH before and after administration of LH/FSH-RH (LRH)'intravenously and intranasally in four amenorrhoic women. and $4 \mathrm{mg}$ given sublingually. All women responded to the intravenous injection with elevation of the plasma levels of LH and FSH. Intranasal administration produced a response similar to that produced by the intravenous injection. The rise in plasma LH after administration by either route was significant $\quad(0.05>\mathrm{P}>0.01) \quad \mathrm{LH} / \mathrm{FSH}-\mathrm{RH}$ given by either route also produced significant rises in plasma FSH (fig. 1).

Sublingual administration produced no response whatsoever in the doses used, which, however, does not exclude the possibility that larger doses would have resulted in such a response.

The investigation thus showed that LH/FSH-RH can release LH and FSH in amenorrhoic women not only when given intravenously ${ }^{5-8}$ but also when administered intranasally. In the future therapeutic use of LH/FSH-RH the intranasal route offers clear practical advantages over the intravenous or intramuscular ${ }^{4}$ route.-We are, etc.,

S. KULLANDER

G. RANNEVIK

J. THORELL

Department of Obstetrics and Gynecology and

Isotope Laboratory,

Malmo General Hospital,

Maimo, Sweden

1 Borglin, N. E., Acta Obstetricia et Gynecologica Scandinavica, $1962,41,238$.

Schally, A. V., et al., Science, 1971, 173, 1036.
Solbach, H. G., and Wiegelmann, W., Lancet, $1973,1,1259$.

Rannevik, G., Thorell, J., Acta Endocrinologica

Nillius,.). S. J. J., and Wide, L., fournal of Obstetrics and Gynaecology of the British Commonwealth, 1972, 79, 874 .

Sciences, pt. 1, P., and Dahlén, H. G., Life Sciences, pt. 1, 1972, 11, 623.

Besser, G. M., Marshall, J. C., McNeilly, A., docrinologica $(K b h), 1973$, suppl. no. 177 , p. 258 .

Rannevik. G., Jeppsson, S., Kullander, S., and suppl. no. 177, p. 293.

Arimura, A., et al., fournal of Clinical Endocrinology, 1973, 36, 385

\section{Cancer and the Patien}

SIR,-I cannot help feeling that Mr. Charles Wright is rather premature with his Personal View (6 October, p. 45). Cancer remains the scourge of our times and even when caught in its early stages the price of "cure" is often high. For example, mastectomy and colostomy are physical stigmata that nobody welcomes.

In Britain I believe we have a healthy respect for the disease, but I am sure I speak for the great majority in challenging Mr. Wright's assertion that we "lie" to patients. To inform a person that he has cancer without histological confirmation or knowledge of possible spread and without being asked causes unnecessary suffering and verges on the unethical.

Of course most terminal patients are aware of their condition, but there is always that slight hope until destroyed by someone. Possibly doctors in North America are losing their compassion. Certainly I have noticed when working alongside them in Britain that they tend to be more blunt. It is not my impression that the patients, or indeed the nursing staff, welcome this approach.

When neoplastic disease can be cured by swallowing tablets-witness the change in attitude towards tuberculosis and mental 